\title{
Thoracotomy for emergency repair of iatrogenic tracheal rupture: single center analysis of perioperative management and outcomes
}

Manuel F. Struck ${ }^{1 *+}$ D, Gunther Hempel ${ }^{1+}$, Uta C. Pietsch ${ }^{1}$, Johannes Broschewitz ${ }^{2}$, Uwe Eichfeld ${ }^{2}$, Robert Werdehausen ${ }^{1}$ and Sebastian Krämer $^{2}$

\begin{abstract}
Background: latrogenic tracheal ruptures are rare but life-threatening airway complications that often require surgical repair. Data on perioperative vital functions and anesthetic regimes are scarce. The goal of this study was to explore comorbidity, perioperative management, complications and outcomes of patients undergoing thoracotomy for surgical repair.

Methods: We retrospectively evaluated adult patients who required right thoracotomy for emergency surgical repair of iatrogenic posterior tracheal ruptures and were admitted to a university hospital over a 15-year period (2004-2018). The analyses included demographic, diagnostic, management and outcome data on preinjury morbidity and perioperative complications.

Results: Thirty-five patients who met the inclusion criteria were analyzed. All but two patients (96\%) presented with critical underlying diseases and/or emergency tracheal intubations. The median time (interquartile range) from diagnosis to surgery was $0.3(0.2-1.0)$ days. The durations of anesthesia, surgery and one-lung ventilation (OLV) were 172 (128-261) min, 100 (68-162) min, and 52 (40-99) min, respectively. The primary airway management approach to OLV was successful in only 12 patients (34\%). Major complications during surgery were observed in 10 patients (29\%). Four patients (11\%) required cardiopulmonary resuscitation, one of whom received extracorporeal membrane oxygenation, and another one of these patients died during surgery. Major complications were associated with significantly higher all-cause 30-day mortality $(p=0.002)$ and adjusted mortality $(p=0.001)$ compared to patients with minor or no complications.

Conclusions: Surgical repair of iatrogenic tracheal ruptures requires advanced perioperative care in a specialized center due to high morbidity and potential complications. Airway management should include early anticipation of alternative OLV approaches to provide acceptable conditions for surgery.
\end{abstract}

Keywords: latrogenic tracheal rupture, Surgical repair, Thoracotomy, Perioperative management, Anesthesia, Airway management, One-lung ventilation, Complication

\footnotetext{
* Correspondence: manuelstruck@web.de

${ }^{\dagger}$ Manuel F. Struck and Gunther Hempel contributed equally to this work.

${ }^{1}$ Department of Anesthesiology and Intensive Care Medicine, University

Hospital Leipzig, Liebigstr.20, 04103 Leipzig, Germany

Full list of author information is available at the end of the article
}

(c) The Author(s). 2019 Open Access This article is distributed under the terms of the Creative Commons Attribution 4.0 International License (http://creativecommons.org/licenses/by/4.0/) which permits unrestricted use, distribution, and reproduction in any medium, provided you give appropriate credit to the original author(s) and the source, provide a link to the Creative Commons license, and indicate if changes were made. The Creative Commons Public Domain Dedication waiver (http://creativecommons.org/publicdomain/zero/1.0/) applies to the data made available in this article, unless otherwise stated. 


\section{Background}

Iatrogenic tracheal ruptures of the posterior membrane are rare but life-threatening airway complications that are associated with emergency tracheal intubation, tracheotomy, and surgery, and blunt and penetrating trauma [1]. The literature gives only rough estimations of its prevalence and incidence and current knowledge results mainly from retrospective studies and case series. Tracheal intubation-related incidence is reported to be approximately $0.005 \%$ for single lumen intubations and may be between 0.05 and $0.19 \%$ for double lumen intubations, while the incidence of iatrogenic tracheal ruptures caused by percutaneous dilation tracheostomies may be as high as $1 \%$ [1-11].

Although conservative and less invasive treatment options have become increasingly popular, larger lesions associated with severe respiratory impairment still require direct surgical repair [1-8]. Surgical approaches from the anterior neck are possible in lesions of the cervical part of the trachea, whereas right thoracotomy under one-lung ventilation $(\mathrm{OLV})$ is the method of choice for lesions of the thoracic trachea, tracheal bifurcation and proximal right main bronchus [1-11]. Surgery includes suture of the lesion, sealing and reinforcement of the sutures [9-11]. Depending on the anatomy and extension of the lesion, perioperative airway management and OLV may require frequent fiber-optic re-evaluation of the tube position to provide the best conditions for surgery.

In the literature, the occurrence of clinically relevant issues (e.g., impaired view of the operating field, cardiopulmonary deterioration, or bleeding) during emergency tracheal surgery is not sufficiently examined, and studies that focus particularly on the course of perioperative vital functions are not available. The goal of this study was to explore perioperative management, complications during surgical repair, and outcomes of iatrogenic tracheal ruptures based on individual comorbidity. Main study endpoint was to detect, whether major perioperative complications may influence patient outcomes compared to none or minor perioperative complications. Based on observed results, we tried to formulate a clinical message and practice implications for the treatment of patients undergoing thoracotomy for surgical repair of iatrogenic tracheal ruptures.

\section{Methods}

\section{Study design and ethics}

We conducted a retrospective single-center cohort study on patients who required thoracotomy for surgical repair of iatrogenic tracheal ruptures. After approval of the Ethics Committee, the database of the University Hospital Leipzig was reviewed to identify patients who were classified by the ICD-10 system for tracheal rupture (ICD-10 code S11.x and S27.x) between 07/2004 and 12/
2018. Iatrogenic tracheal rupture was defined as a lesion of the posterior part of the trachea caused by tracheal intubation, tracheotomy, surgery, and blunt and penetrating trauma. Patients with incomplete documentation, anterior tracheal injury, cervical surgical approach without OLV, conservative approach and age under 18 years old were excluded. The study protocol adheres to the STROBE guidelines for uniform reporting of observational studies. The University Hospital Leipzig is a 1350-beds academic medical center that provides advanced emergency care and a referral center for acute respiratory distress syndrome (ARDS) and extracorporeal membrane oxygenation (ECMO). All interdisciplinary specialists for the treatment of tracheal ruptures are available $24 / 7$, i.e., anesthetists and critical care specialists, endoscopy teams (pulmonologists and gastroenterologists), radiologists, otolaryngologists, and thoracic and upper gastrointestinal surgeons.

\section{General management}

Patients with suspected iatrogenic tracheal rupture were referred by emergency medical service (EMS) transport from other hospitals or were already admitted to the intensive care unit (ICU), the normal ward or the operating room of the university hospital. After diagnostic confirmation using fiber-optic bronchoscopy and chest computed tomography (CT), all patients were admitted (or had already been admitted) to the ICU. The decision for surgery was made by a team approach including attending thoracic surgeons, pulmonologists and critical care physicians according to patients' condition, rupture size, injury mechanism and diagnostic findings (e.g., mediastinitis, pneumothorax, pleural effusion). Emergency surgery was scheduled, and the patients were transferred to the operating room and underwent thoracotomy for surgical repair following general anesthesia and one-lung ventilation. Patients were returned to the ICU postoperatively.

Patients were analyzed for demographic data, including age, body mass index, morbidity (American Society of Anesthesiologists, ASA, classification), sequential organ failure assessment (SOFA) and simplified acute physiology score revision two (SAPS II) before tracheal rupture, size and anatomy of the lesion, anesthesia regimen, airway management (e.g., tube advancement into one main-stem bronchus, double-lumen tube (DLT), bronchus blocker), surgical procedures, suture reinforcement techniques, process times of anesthesia, surgery and OLV, $\mathrm{paO}_{2} / \mathrm{FiO}_{2}$ ratios $(\mathrm{p} / \mathrm{f})$ and serum lactate levels before and after surgery, proportion of pure oxygen ventilation, peak inspiratory pressures (PIP) and positive end expiratory pressures (PEEP), lowest $\mathrm{SpO}_{2}$ levels, highest end-tidal $\mathrm{CO}_{2}$ levels, lowest systolic blood pressure (SBP), highest noradrenaline dosage, adrenaline and dobutamine administration, fluid volumes, transfusion amount, total blood loss, 
urinary output, length of stay in the ICU (LOS ICU), ventilator days after surgery, and all-cause and adjusted 30day mortality.

Perioperative complications were analyzed and classified as none, minor and major complications. Minor complications were defined as the occurrence of at least one of the following criteria: one necessary change of airway management to establish sufficient OLV, mild to moderately impaired visualization of the situs, noradrenaline dosage $>0$ and $\leq$ $0.5 \mu \mathrm{gg} \mathrm{min}^{-1}$, adrenaline dosage $>0$ and $<1 \mathrm{mg}$, oliguria and anuria, and short-term hypotension ( $\mathrm{SBP}<90 \mathrm{mmHg}$ ), hypoxemia $\left(\mathrm{SpO}_{2}<90 \%\right)$ and hypercapnia $\left(\mathrm{etCO}_{2}>50\right.$ $\mathrm{mmHg}$ ). Major complications were defined as cardiac arrest,

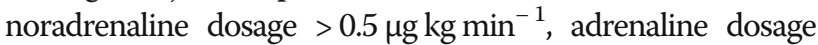
$\geq 1.0 \mathrm{mg}$, transfusion of greater than four units of red blood cells (RBC), fresh frozen plasma (FFP) or platelets in total, more than one required change of airway management to achieve sufficient OLV, severely impaired visualization of the situs, and sustained hypotension, hypercapnia or hypoxemia despite documented efforts of treatment.

Data from perioperative management were obtained electronically, including automatic transfer of monitored vital functions (heart rate, $\mathrm{SpO}_{2}$, etCO ${ }_{2}$, arterial blood pressure, central venous pressure, body temperature via urinary bladder sensor or rectal probe) and anesthesia unit $\left(\mathrm{FiO}_{2}\right.$, inspiratory and end-expiratory anesthesia gas concentrations, minute volumes) using the electronic COPRA patient data management system (COPRA system $\mathrm{GmbH}$, Berlin, Germany). Due to automatic electronic data transfer, a reliable continuous data collection without missing data was guaranteed in the presented data. Additional electronic or paper-based documentation was included in the analysis if present.

\section{Statistical analysis}

Data are reported as medians (interquartile range, $\mathrm{IQR})$, and counts (percentage), unless indicated otherwise. Due to heterogeneity of patients, unspecific underlying causes, and rare and unpredictable emergency conditions, a precise sample size calculation was not possible for this study but we expected a patient number of at least two patients per analyzed year, according to previous studies of our and other centers [1-11]. Statistical comparisons between patients with and without major perioperative complications were performed using the $X^{2}$ test and Fisher's exact test for qualitative data, and the Mann-Whitney U-test was used for quantitative data. The alpha level of significance was set at 0.05. All tests were two-tailed. Multivariate analysis was not performed due to the small sample size. Statistical analyses were performed using IBM SPSS Statistics for Windows, version 24.0 (IBM Corp., Armonk, NY, United States).

\section{Results}

During the study period, 83 patients were identified according to their classification as ICD-10 code S11.x (open wounds to the trachea) and S27.x (open wounds to the thoracic trachea). Twenty-five patients were excluded due to absence of tracheobronchial injury, multiple coding or elective surgery. Of the remaining 58 patients, 20 patients had tracheobronchial rupture treated conservatively (with or without stent therapy) and three underwent minimal invasive surgery (anterior approach) without thoracotomy. Thirty-five patients met the inclusion criteria and were subject of the study (Figs. 1 and 2).

\section{Patients' characteristics}

There were 25 female patients (71\%) and 10 male patients $(29 \%)$ with a median age of 67 years (range 26-86 years). One-half of the patients $(n=17,49 \%)$ were referred from other hospitals. All but two patients (96\%) presented with critical conditions (ASA III-VI) prior to iatrogenic tracheal rupture, including one patient who required extracorporeal lung assist (ECLA) due to severe hypercapnia (Fig. 3). Nineteen patients (54\%) were already admitted to the ICU prior iatrogenic tracheal rupture and seven patients (20\%) underwent emergency tracheal intubation due to cardiopulmonary resuscitation (CPR). The main cause of tracheal rupture was tracheal intubation $(n=20,57 \%)$, followed by tracheotomyrelated causes $(n=9,26 \%)$ (four percutaneous dilatation tracheotomy (PDT), two surgical tracheotomy, two lesions associated with tracheal cannula reinsertion, and one during bronchoscopy), and surgical injuries $(n=6$, 17\%) (three patients each with esophageal and otolaryngeal surgery) (Fig. 2). Subcutaneous emphysema as a primary symptom was present in 27 patients (77\%), and three patients $(9 \%)$ primarily presented with signs of mediastinitis, with two of these occurrences after esophageal surgery and one occurrence after emergency tracheal intubation due to severe exacerbation of chronic obstructive pulmonary disease and delayed referral. Further data on demography and comorbidity are presented in Table 1.

\section{Perioperative management}

Times from rupture to surgery and process times of anesthesia, surgery and OLV are presented in Table 1 and Fig. 4. Thirty-one patients (89\%) were already under general anesthesia and mechanical ventilation prior to operating room admission. The remaining four patients (11\%) underwent induction of general anesthesia in the operating room, one of whom required awake fiberoptic intubation due to oropharyngeal cancer and anticipated difficult airway. In all but three patients, arterial cannulation for invasive blood pressure monitoring and central venous catheterization $(\mathrm{CVC})$ were already 


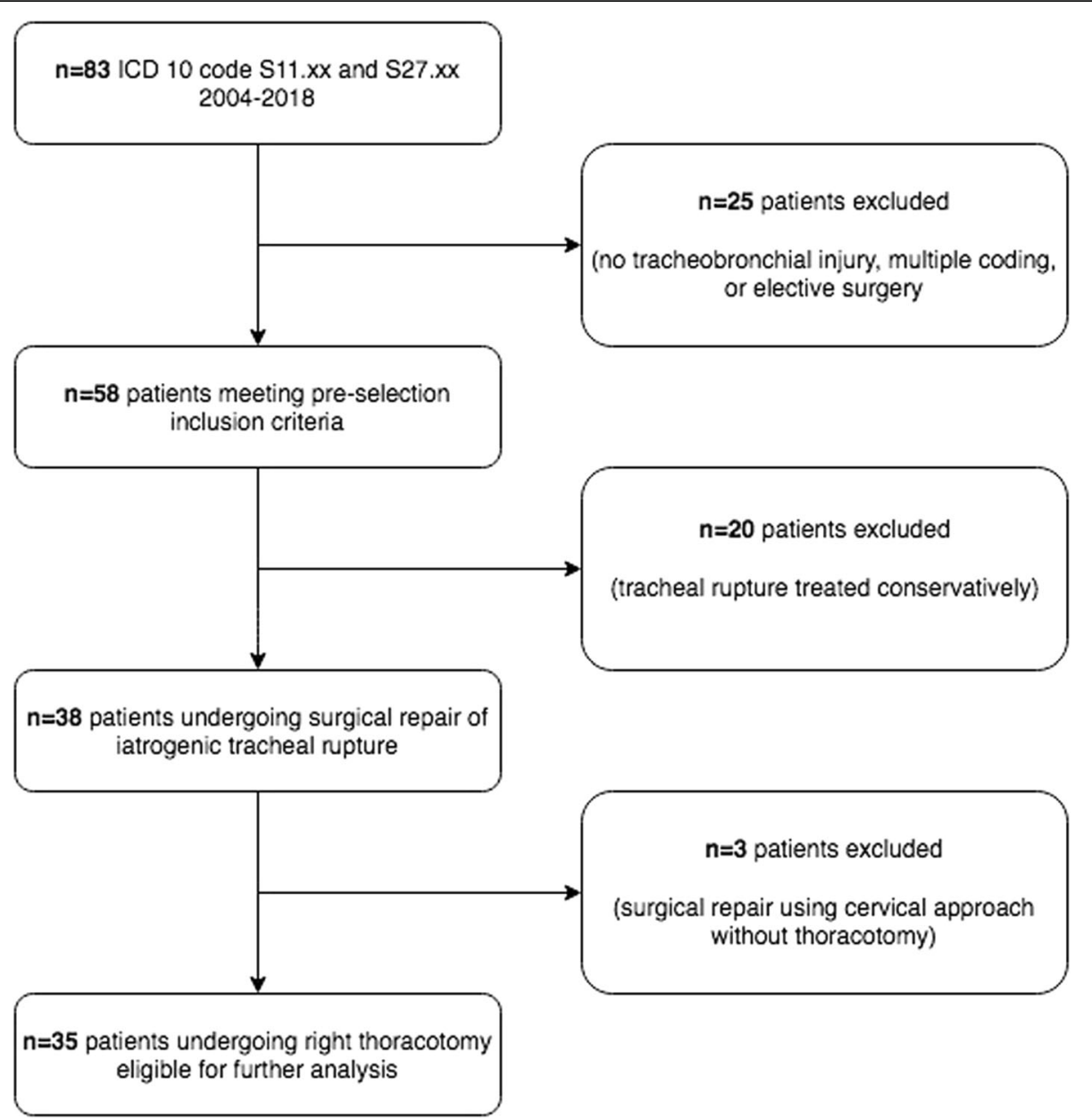

Fig. 1 Study flow chart

established in the ICU. Two patients received CVC after anesthesia induction, and one patient received it during surgery.

Propofol was used for anesthesia induction in $32 \mathrm{pa}-$ tients (91\%), and nine patients (26\%) underwent genuine propofol-based TIVA. Five patients received additional midazolam and midazolam/ketamine administration, and two patients received only midazolam. All patients received sufentanil for analgesia (seven patients received repeated bolus administrations, and 28 patients had continuous administration), and two patients were primarily induced with remifentanil (later replaced by sufentanil). Rocuronium was used for neuromuscular blockade in most patients $(n=32,91 \%)$; two patients received pancuronium, and one patient received cis-atracurium due to liver failure. The anesthesia regimen included volatile and total intravenous anesthesia (TIVA) approaches, which were chosen at the discretion of the attending anesthetist (Table 1). Volatile anesthesia was applied in 19 patients (54\%), and 16 of these patients received isoflurane, two received desflurane, and one received sevoflurane. Four patients who received volatile anesthesia received additional intravenous propofol and midazolam administration. Sixteen patients (46\%) underwent TIVA, three of these patients secondary to volatile anesthesia approaches with the development of air leakage and exposure of anesthesia gases towards the operating team after OLV. All patients were transferred to the ICU under mechanical ventilation with propofol or midazolam sedation after surgery.

\section{Airway management and one-lung ventilation}

Most patients $(n=27,77 \%)$ underwent tube advancement into one main-stem bronchus for OLV. Two of these patients underwent additional approaches with bronchus blockers, and one patient received a bronchus blocker without previous tube advancement. Eleven patients (31\%) had DLT placement, four of these placements were secondary to previous single-lumen tube advancements into one main bronchus without sufficient OLV conditions. All OLV approaches were monitored using fiber-optic bronchoscopy. Of the nine patients 


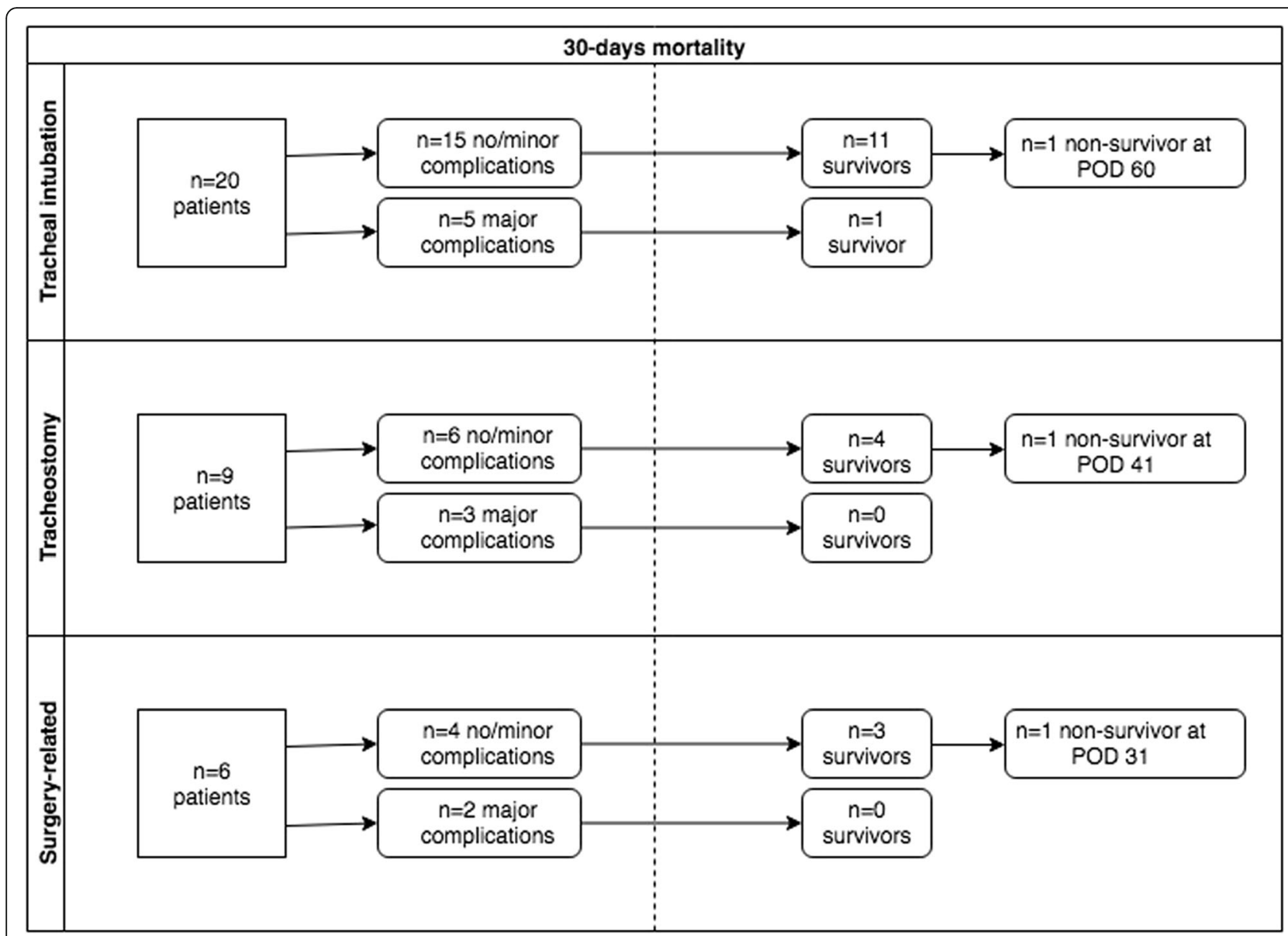

Fig. 2 Linear flow chart of different causes of iatrogenic tracheal ruptures. POD: post-operative day

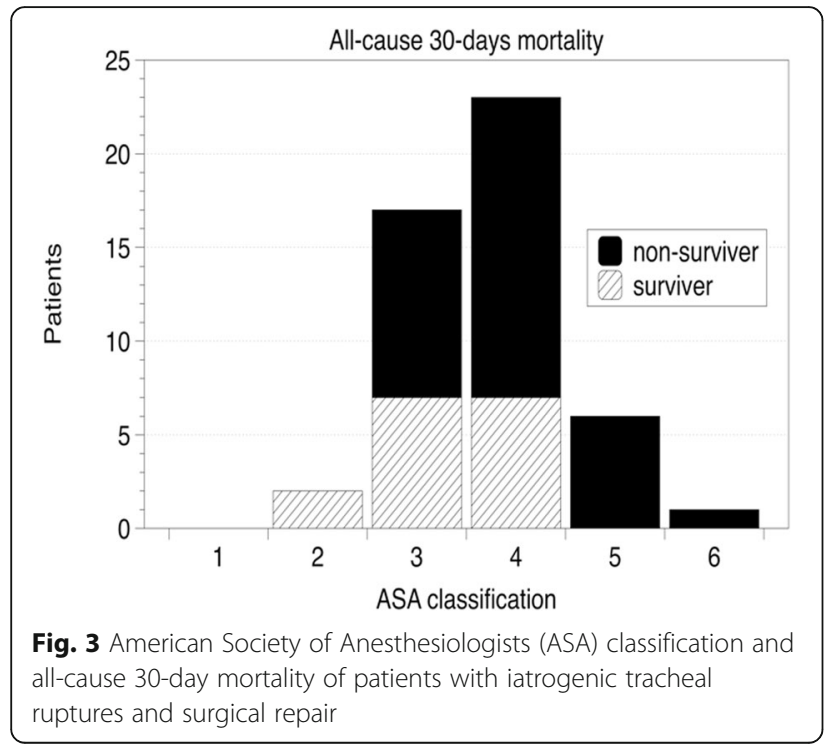

who had tracheostoma-related tracheal ruptures, four underwent orotracheal single-lumen tube intubation, another four underwent single-lumen intubation via tracheostomy, and one underwent double-lumen tracheal-cannula insertion for perioperative airway management.

The successful establishment of OLV required one tube exchange in eight patients (23\%). Two exchanges were necessary in another 12 patients (34\%), and three patients (9\%) required three exchanges. Therefore, primary tube placement was successful in the remaining 12 patients (34\%). Notably, only one of the 11 patients with DLT did not require tube exchanges. The respiratory variables before, during and after surgery are shown in Table 1.

OLV approaches were associated with intermittent circulatory arrest in four patients. OLV remained impossible in two of these patients. One patient was operated under ECMO support and weaned off the ECMO directly after surgery (ECMO duration $2 \mathrm{~h}$ ). Another patient died in the operating room after prolonged cardiopulmonary resuscitation (CPR) efforts.

Iatrogenic tube cuff lesions and tube damage due to surgery were observed in five cases, most likely because 
Table 1 Demography, clinical presentation, perioperative care, and outcomes of patients with iatrogenic tracheal rupture

\begin{tabular}{|c|c|c|c|c|}
\hline & Total $(n=35)$ & No and minor complications $(n=25)$ & Major complications $(n=10)$ & $P$ \\
\hline Age, years & $67(55-76)$ & $61(53-73)$ & $75(58-82)$ & 0.125 \\
\hline Female & $25(71)$ & $18(72)$ & $7(70)$ & 0.100 \\
\hline BMI Clinical presentation & $26(24-31)$ & $27(27-32)$ & $24(21-29)$ & 0.213 \\
\hline ASA & $4(3-4)$ & $4.0(3-4)$ & $4.0(3.75-5)$ & 0.313 \\
\hline ICU before rupture & $19(54.3)$ & $14(56)$ & $5(50)$ & 0.100 \\
\hline CPR before rupture & $7(20)$ & $5(20)$ & $2(20)$ & 0.100 \\
\hline SAPS $\|$ & $52(36-58)$ & $49(33-58)$ & $56(49-67)$ & 0.339 \\
\hline SOFA & $7(4-9)$ & $7(4-9)$ & $6(5-9)$ & 0.567 \\
\hline Tear length, cm & $5(4-6)$ & $5(4-6)$ & $4(4-6)$ & 0.737 \\
\hline Causative events & & & & 0.438 \\
\hline Tracheal intubation & $20(57)$ & $15(60)$ & $5(50)$ & \\
\hline Emergency intubation & $18(51)$ & $13(52)$ & $5(50)$ & \\
\hline Tracheotomy & $9(26)$ & $7(28)$ & $2(20)$ & \\
\hline Surgery & $6(17)$ & $3(12)$ & $3(30)$ & \\
\hline Interfacility EMS referral & $17(49)$ & $11(44)$ & $6(60)$ & 0.392 \\
\hline \multicolumn{5}{|l|}{ Process times } \\
\hline Rupture to surgery, days & $0.3(0.2-1.0)$ & $0.3(0.2-0.8)$ & $0.7(0.2-3.4)$ & 0.272 \\
\hline Anesthesia, minutes & $172(128-261)$ & $160(125-209)$ & $243(149-304)$ & 0.093 \\
\hline Surgery, minutes & $100(68-162)$ & $97(64-121)$ & $141(78-222)$ & 0.265 \\
\hline OLV, minutes & $52(40-99)$ & $55(40-91)$ & $63(46-109)$ & 0.401 \\
\hline \multicolumn{5}{|l|}{ Anesthesia management } \\
\hline TIVA & $16(45.7)$ & $12(48)$ & $4(40)$ & 0.723 \\
\hline Tube advancement & $27(77)$ & $18(72)$ & $9(90)$ & 0.390 \\
\hline DLT & $11(31)$ & $4(4.9)$ & $0(0.0)$ & 0.120 \\
\hline Bronchus blocker & $3(9)$ & $1(4)$ & $2(20)$ & 0.190 \\
\hline Devices during surgery & $1(0-2)$ & $1(0-2)$ & $2(0-2)$ & 0.388 \\
\hline \multicolumn{5}{|l|}{ Tracheotomy } \\
\hline Before surgery & $7(20)$ & $4(16)$ & $3(30)$ & 0.761 \\
\hline During surgery & $6(17)$ & $5(20)$ & $1(10)$ & \\
\hline After surgery & $7(20)$ & $5(20)$ & $2(20)$ & \\
\hline Not performed & $15(43)$ & $11(44)$ & $4(40)$ & \\
\hline \multicolumn{5}{|l|}{ Respiratory variables } \\
\hline $\mathrm{FiO}_{2} 1.0, \%$ & $90(75-100)$ & $90(55-100)$ & $95(80-100)$ & 0.547 \\
\hline $\mathrm{FiO}_{2}$ other & $0.62(0.5-0.8)$ & $0.6(0.5-0.75)$ & $0.65(0.45-0.8)$ & 0.961 \\
\hline $\mathrm{p} / \mathrm{f}$ ratio before & $141(110-219)$ & $133(115-212)$ & $157(101-315)$ & 0.860 \\
\hline $\mathrm{p} / \mathrm{f}$ after & $143(111-153)$ & $144(133-154)$ & $97(80-236)$ & 0.042 \\
\hline $\mathrm{SaO}_{2}$ lowest, $\%$ & $76(54-85)$ & $84(65-88)$ & $54(24-72)$ & 0.002 \\
\hline etCO 2 highest, $\mathrm{mmHg}$ & $46(41-59)$ & $45(40-59)$ & $51(42-60)$ & 0.410 \\
\hline PIP highest, mmHg & $25(25-28)$ & $25(25-29)$ & $25(25-28)$ & 0.621 \\
\hline PEEP highest, mmHg & $10(8-12)$ & $10(8-11)$ & $10(8-12)$ & 0.509 \\
\hline \multicolumn{5}{|l|}{ Circulation } \\
\hline SBP lowest, mmHg & $74(52-82)$ & $80(70-86)$ & $40(0-72)$ & $<0.001$ \\
\hline Noradrenaline, $\mu \mathrm{g} \mathrm{kg} \mathrm{min}{ }^{-1}$ & $0.18(0.1-0.31)$ & $0.10(0.06-0.22)$ & $0.22(0.2-0.84)$ & a \\
\hline Adrenaline & $8(22.9)$ & $1(4)$ & $7(70)$ & a \\
\hline
\end{tabular}


Table 1 Demography, clinical presentation, perioperative care, and outcomes of patients with iatrogenic tracheal rupture (Continued)

\begin{tabular}{|c|c|c|c|c|}
\hline & Total $(n=35)$ & No and minor complications $(n=25)$ & Major complications $(n=10)$ & $P$ \\
\hline Dobutamine & $9(25.7)$ & $5(20)$ & $4(40)$ & 0.398 \\
\hline Crystalloid, L & $2(1-2.5)$ & $1.5(1-2)$ & $2.5(1-4)$ & 0.009 \\
\hline Transfusion & $14(40)$ & $8(32)$ & $6(60)$ & 0.151 \\
\hline Blood loss, ml & $450(250-750)$ & $350(250-575)$ & $725(312-1150)$ & 0.107 \\
\hline Lactate before, $\mathrm{mmol} / \mathrm{l}$ & $1.3(0.8-2.6)$ & $1.4(1-2.6)$ & $1.1(0.7-2.4)$ & 0.604 \\
\hline Lactate after, mmol// & $1.4(1.1-3.1)$ & $1.3(0.9-2.9)$ & $2.8(1.5-5.6)$ & 0.083 \\
\hline Urinary output, ml & $50(0-100)$ & $50(0-100)$ & $25(0-162)$ & 0.734 \\
\hline \multicolumn{5}{|l|}{ Outcome } \\
\hline Ventilator days & $9(4-18)$ & $10(4-25)$ & $8(3-14)$ & 0.494 \\
\hline LOS ICU, days & $10(6-24)$ & $11(6-33)$ & $9(5-14)$ & 0.118 \\
\hline All-cause 30-day mortality & $16(46)$ & $7(28)$ & $9(90)$ & 0.002 \\
\hline Adjusted mortality & $7(20)$ & $1(4)$ & $6(60)$ & 0.001 \\
\hline
\end{tabular}

Data are medians (IQR) and counts (\%); ${ }^{\text {, }}$ comparisons not applicable due to categorization; BMI body mass index, ASA American Society of Anesthesiologists classification, ICU intensive care unit, CPR cardiopulmonary resuscitation, SAPS I/ simplified acute physiology score revision two, SOFA sequential organ failure assessment, EMS emergency medical service, OLV one-lung ventilation, $D L T$ double lumen tube, $p / f \mathrm{paO}_{2} / \mathrm{FiO}_{2}$-ratio, $P I P$ peak inspiratory pressure, PEEP positive end-expiratory pressure, LOS length of stay. $P$ values below 0.05 are significant

of the very close proximity to the surgical field. In one case, the cuff was inadvertently sutured, and parts of the cuff were retrieved postoperatively via bronchoscopy. From the five patients with cuff lesion, a pharyngeal tamponade provided acceptable ventilation conditions in three patients. Airway leakage was minimal in the remaining two patients, and no further measures were necessary.

$\mathrm{FiO}_{2}$ during OLV varied considerably while 17 patients (49\%) were ventilated with pure oxygen during the entire operation period. Eighteen patients had a median proportion of pure oxygen ventilation during $90 \%$ of the operating period, and the median $\mathrm{FiO}_{2}$ in the remaining time

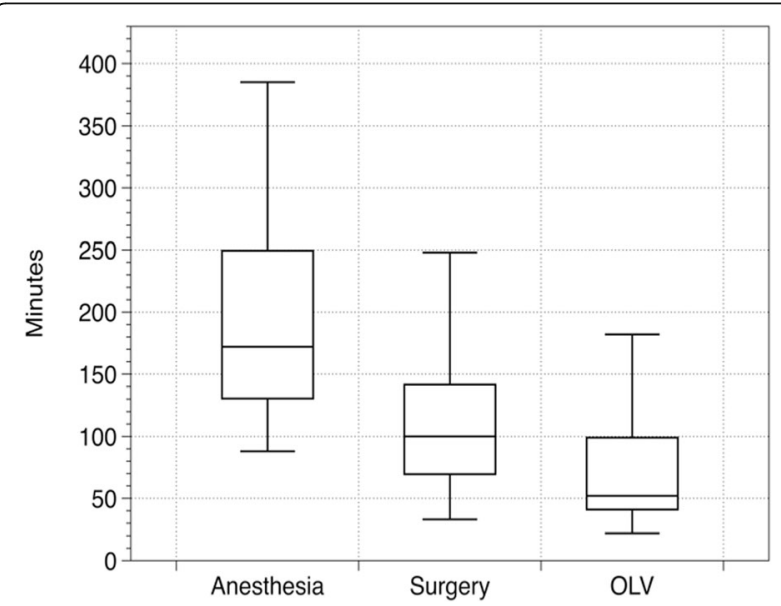

Fig. 4 Procedure durations of surgical repair of iatrogenic tracheal ruptures. In the boxes, the dark horizontal line represents the median, and the box represents the 25th and 75th percentiles, the whiskers are the 5th and 95th percentiles. OLV: one-lung ventilation was 0.62 . Patients with no and minor complications were comparable with patients who presented with major complications in the median $\mathrm{FiO}_{2}$, the p/f-ratio before surgery, and the highest etCO $\mathrm{O}_{2}$, PIP and PEEP levels, and they exhibited significant differences in $\mathrm{p} / \mathrm{f}$-ratios after surgery $(p=0.042)$ and lowest $\mathrm{SpO}_{2}(p=0.002)$ (Table 1).

Postoperatively, eleven patients underwent another tracheal tube exchange for DLT removal or for a tube with a larger diameter. Tracheotomy was performed prior to tracheal rupture in seven patients (being the cause of tracheal rupture in five cases), during tracheal surgery in six patients and after tracheal surgery in another six patients at the ICU after a median of three days (range 0-9 days). Fifteen patients did not undergo tracheotomy. All of the 34 patients who were postoperatively admitted to the ICU underwent frequent bronchoscopy re-evaluations.

\section{Circulation}

Twenty-eight patients received continuous noradrenaline administration for circulation stabilization with the median highest noradrenaline dosage of $0.18(0.1-0.31) \mu \mathrm{g}$ $\mathrm{kg} \mathrm{min}^{-1}$. Nine patients received dobutamine, and another eight patients (including four who received dobutamine) received adrenaline. The median perioperative fluid administration was 2000 (1000-2500) ml using Ringers acetate, and six patients received additional $6 \%$ hydroxyethyl starch $(500 \mathrm{ml}$ each). Blood transfusion was required in fourteen patients (40\%). Eight patients received only RBCs, four patients RBCs and FFP, and two patients received $\mathrm{RBCs}$ and platelet concentrates. The median total blood loss was $450(250-750) \mathrm{ml}$, and the median total urinary output was $50(0-100) \mathrm{ml}$. Thirteen patients (37\%) had anuria during surgery, and 
four patients required cardiopulmonary resuscitation. Patients with major perioperative complications had significantly lower lowest SBP $(p<0.001)$, and received larger volumes of crystalloids $(p=0.009)$ compared to patients who had no and minor complications (Table 1).

\section{Surgery}

Broad-spectrum antibiotic therapy was initiated prior to surgery in 31 patients $(89 \%)$, primarily using carbapenem (55\%). Twenty-six patients (74\%) received additional antibiotic administration prior to skin incision in the operating room. Tracheal suturing was performed in all patients, and sutures were reinforced in 29 patients (83\%) using artificial tissues (e.g., TachoSil ${ }^{\circ}$, TachoComb ${ }^{\circ}$, Sulmycin $^{\circ}$ ) in nine patients and additional autologous tissue patches/flaps (e.g., pleura, pericardium, thymus, latissimus dorsi muscle and stylohyoid muscle) in 20 patients. Right-side chest tubes were inserted in all patients, and five patients received additional left side chest tubes due to pneumothorax. Surgical revisions were required in six patients (17\%), of whom three underwent one revision and one underwent two revisions. Two patients with suture insufficiency after the first surgery could not be revised. One of these patients was too unstable for revision and died on postoperative day (POD) two, and the other patient died due to coincidental rupture of an aortic aneurysm during transfer to the operating room.

\section{Outcomes}

The median length of stay in the ICU was $10(6-24)$ days, including 9 (4-18) ventilator days (Table 1). With regard to preinjury morbidity, both patients with ASA III survived, but all-cause 30-day survival rates of patients with ASA III was $70 \%$ (7 of 10), ASA IV was $44 \%$ (7 of 16) and ASA V-VI was $0 \%$ (0 of 7) (Fig. 3). One patient was classified as ASA VI due to severe blunt trauma that included a nonsurvivable traumatic brain injury. This patient underwent prehospital CPR and difficult emergency intubation, which caused the tracheal rupture. After surgical repair and brain death protocol completion, the patient underwent organ donation of heart, liver and kidneys. Mortality related to tracheal surgery was $20 \%$ ( $n=7$ patients), including one patient who died in the operating room during surgery. All-cause 30-day mortality was $46 \%(n=17)$. Eleven patients $(65 \%)$ died from sepsis/multiorgan failure, and six (35\%) patients died from acute cardiopulmonary decompensation (including the patient with aortic rupture on the way to surgical revision). Three more patients died after 30 days. One of these patients died due to fulminant mediastinitis on POD 31, and two patients died from cardiopulmonary decompensation on POD 41 and cerebral ischemia on POD 60 . Patients with major complications had significantly higher all-cause 30-day mortality $(p=0.002)$ and adjusted mortality $(p=0.001)$ compared to patients who had no and minor complications.

\section{Discussion \\ Key results}

Thoracotomy for the surgical repair of iatrogenic tracheal ruptures is an emergency operation that is performed 2-3 times annually in our center, which is consistent with earlier data of our and other centers [3-7]. Because minor tracheal lesions are treated conservatively, and some lesions remain undetected, the true incidence of iatrogenic tracheal ruptures requiring surgical repairs is difficult to estimate [1-11]. Our results demonstrated the perioperative management and incidence of perioperative complications of a single center. The results of our study suggest that patients with iatrogenic tracheal ruptures present with considerable preinjury morbidity. Only a small number of our patients presented with ASA I or II, and most patients were already admitted to the ICU or underwent emergency tracheal intubation for cardiopulmonary resuscitation. We found that high preinjury morbidity may result in poor outcomes even with advanced healthcare resources, including specialized hospital infrastructures and medical expertise. Our results also indicate that major perioperative complications in these patients are associated with further deterioration of adjusted and all-cause 30-day mortality compared to patients with no and minor complications. Our all-cause 30-day mortality rate of $46 \%$ is consistent with the published literature, but other centers reported lower and higher mortality rates up to $70 \%[1,3,4,8,11]$. However, detailed data of preinjury conditions are missing in most studies. Whether surgery should be avoided in highly morbid patients remains unanswered because potentially associated perioperative complications may be preventable or treatable. The decision to perform surgical repair should be made carefully depending on individual circumstances and keeping in mind that conservative approaches do not necessarily provide substantially better outcomes [2].

\section{Interpretation}

We regard appropriate airway management and sufficient OLV as key measures for successful surgery. Tube advancement into one main-stem bronchus was the most common approach in our study, and DLT was used in only one-third of cases. This use is consistent with other centers that reported similar airway strategies [5]. Our data also reveal that intraoperative changes of airway devices were required frequently. In most cases, the tube was too large or too short and could not be advanced properly into one main-stem bronchus below the tracheal rupture and required replacement and insertion of a smaller and/or longer tube or DLT. OLV resulted in severe cardiopulmonary complications in almost onethird of our patients, including four patients who required 
CPR. Two patients did not tolerate OLV at all, and one patient received ECMO, which may be an emergency option for tracheal surgery when OLV is not possible $[12,13]$. Transient hypoxemia in OLV is a common complication, and fiber-optic monitoring of tube position, adjustment of ventilation strategy and increasing the $\mathrm{FiO}_{2}$ prevent longer episodes [14, 15]. We observed a high proportion of pure oxygen ventilation despite considerably low levels of lowest $\mathrm{SpO}_{2}$. Although it may be presumed that patients with already impaired gas exchange may have had a higher probability of pure oxygen ventilation, proportions were comparable in both groups and thus did not influence outcome statistically. Compared to other studies of OLV in the setting of surgical repair of iatrogenic ruptures, our average PEEP levels were high [8]. The reason for the common practice of the application of low PIP and PEEP levels during tracheal surgery is to avoid shear stress in the respiratory system [5]. However, in prospective randomized clinical trials, lung-protective ventilation strategies during OLV did not improve gas exchange compared with conventional ventilation patterns [16]. Alternative airway approaches for surgical repair of iatrogenic tracheal ruptures include high-frequency jet ventilation (HFJV). Although it was not applied in our study collective, HFJV provides similar visualization of the operating field and may be a feasible alternative to DLT [17-19].

Although volatile anesthesia is generally assumed to exhibit lower shunt volumes and less inflammatory response in OLV, randomized controlled trials did not find relevant benefits compared to TIVA [20-23]. More than half of the patients in our study received volatile anesthesia, but volatile anesthesia was changed to TIVA in some patients because of gas exposure to the surgical team. Due to possible airway leakage during surgery under emergency conditions, the anesthetic approach should include a possibility to rapidly change from volatile anesthesia to TIVA.

We observed severe hypotensive episodes during OLV in our patients who required advanced fluid resuscitation, transfusion of blood products and administration of vasopressors and inotropic agents. This necessity reflects the high comorbidity of the study cohort and warrants arterial cannulation and CVC placement for this type of surgery. We did not perform perioperative advanced hemodynamic monitoring (i.e., cardiac output measurements) in our study cohort, and there is no evidence for its benefit in patients undergoing OLV (e.g., for prevention of over-infusion) $[24,25]$. However, preexisting conditions and underlying diseases must be taken into account and should be considered carefully during circulation management.

\section{Limitations}

Because of the general limitations of retrospective observations, small sample sizes and a heterogeneous patient cohort, we must acknowledge the high mortality rates of our study, which may reflect the comorbidity of our patients and may not be comparable to other studies of healthier patients. Furthermore, the results may not be generalizable to the general population due to the single center study design. The treatment of our patients was not standardized apart from the surgical approach. Although only experienced anesthetists and surgeons were involved, different treatment approaches may have influenced individual patient outcome. Nevertheless, the present study provides new data on the emergency treatment of a rare patient cohort under real-life conditions.

\section{Conclusions}

In our study, the comorbidity of patients undergoing thoracotomy for surgical repair of tracheal perforation was considerably high. The perioperative management required different individual approaches of airway management and circulation support. Patients with major perioperative complications were associated with higher postoperative morbidity and mortality. With regard to underlying diseases, we recommend close interdisciplinary communication to manage critical episodes appropriately and safely. Precautions for airway management should include early anticipation of alternative one-lung ventilation approaches to provide acceptable conditions for surgery.

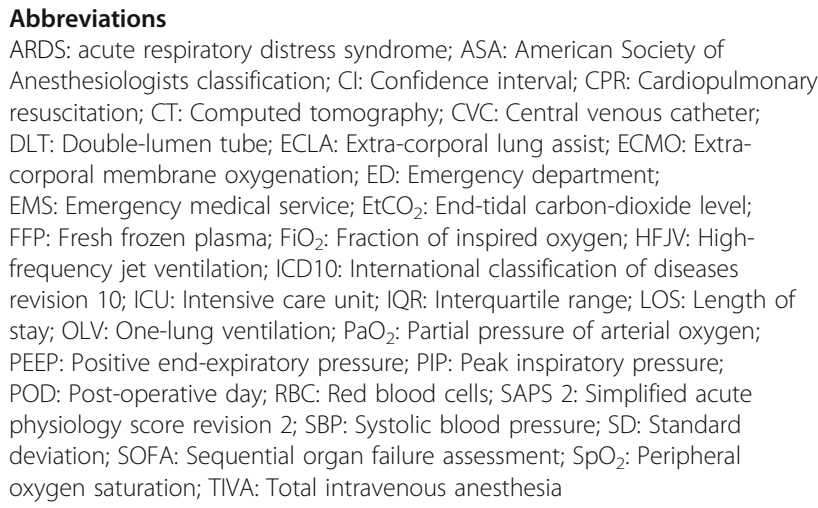

\section{Acknowledgments}

We acknowledge support from the German Research Foundation (DFG) and University of Leipzig within the program of Open Access Publishing.

\section{Authors' contributions}

SK and MFS performed the study design and data analysis and wrote the manuscript. MFS drafted the manuscript. GH conceived of the study and performed the statistical analyses. UCP, JB, UE, and RW conceived of the study and revised the manuscript. All authors read and approved the final manuscript.

Funding

There was no funding obtained for this study.

Availability of data and materials

The datasets used and analyzed during the current study are available from the corresponding author upon reasonable request. 


\section{Ethics approval and consent to participate}

The Ethical Committee at the Medical Faculty, Leipzig University, Leipzig, Germany waived the need for ethical approval (IRB00001750, project ID 484/ 18ek). All administrative permissions were obtained to access and use the medical records of this study. Consent to participate was not applicable due to the retrospective nature of the study.

\section{Consent for publication}

Not applicable.

\section{Competing interests}

The authors declare that they have no competing interests.

\section{Author details}

'Department of Anesthesiology and Intensive Care Medicine, University Hospital Leipzig, Liebigstr.20, 04103 Leipzig, Germany. ${ }^{2}$ Department of Visceral, Transplantation, Thoracic and Vascular Surgery, University Hospital Leipzig, Liebigstr. 20, 04103 Leipzig, Germany.

Received: 11 June 2019 Accepted: 17 October 2019

Published online: 27 October 2019

\section{References}

1. Miñambres E, Burón J, Ballesteros MA, Llorca J, Muñoz P, González-Castro A. Tracheal rupture after endotracheal intubation: a literature systematic review. Eur J Cardiothorac Surg. 2009;35:1056-62.

2. Lee SK, Kim DH, Lee SK, Kim YD, Cho JS. I H. does surgical repair still have a role for iatrogenic tracheobronchial rupture? Clinical analysis of a thoracic Surgeon's opinion. Ann Thorac Cardiovasc Surg. 2016;22:348-53.

3. Meyer M. Latrogenic tracheobronchial lesions--a report on 13 cases. Thorac Cardiovasc Surg. 2001:49:115-9.

4. Hofmann HS, Rettig G, Radke J, Neef H, Silber RE. latrogenic ruptures of the tracheobronchial tree. Fur J Cardiothorac Surg. 2002;21:649-52.

5. Schneider T, Storz K, Dienemann H, Hoffmann H. Management of iatrogenic tracheobronchial injuries: a retrospective analysis of 29 cases. Ann Thorac Surg. 2007;83(6):1960-4.

6. Leinung S, Ott R, Schuster E, Eichfeld U. Tracheobronchial ruptures: classification and management. Chirurg. 2005;76:783-8.

7. Leinung S, Möbius C, Hofmann HS, Ott R, Rüffert H, Schuster E, et al. latrogenic tracheobronchial ruptures - treatment and outcomes. Interact Cardiovasc Thorac Surg. 2006;5:303-6.

8. Deja M, Menk M, Heidenhain C, Spies CD, Heymann A, Weidemann H, et al. Strategies for diagnosis and treatment of iatrogenic tracheal ruptures. Minerva Anestesiol. 2011:77:1155-66.

9. Carretta A, Melloni G, Bandiera A, Negri G, Voci C, Zannini P. Conservative and surgical treatment of acute posttraumatic tracheobronchial injuries. World J Surg. 2011;35:2568-74.

10. Welter S. Repair of tracheobronchial injuries. Thorac Surg Clin. 2014;24: 41-50.

11. Grewal HS, Dangayach NS, Ahmad U, Ghosh S, Gildea T, Mehta AC. Treatment of tracheobronchial injuries: a contemporary review. Chest. 2019; 155:595-604.

12. Rinieri P, Peillon C, Bessou JP, Veber B, Falcoz PE, Melki J, et al. National review of use of extracorporeal membrane oxygenation as respiratory support in thoracic surgery excluding lung transplantation. Eur J Cardiothorac Surg. 2015;47:87-94.

13. Kelly B, Carton E. Extended indications for extracorporeal membrane oxygenation in the operating room. J Intensive Care Med. 2019;23: 885066619842537. https://doi.org/10.1177/0885066619842537 [Epub ahead of print].

14. Karzai W, Schwarzkopf K. Hypoxemia during one-lung ventilation: prediction, prevention, and treatment. Anesthesiology. 2009;110:1402-11.

15. Campos $\mathrm{JH}$, Feider A. Hypoxia during one-lung ventilation-a review and update. J Cardiothorac Vasc Anesth. 2018:32:2330-8.

16. El Tahan MR, Pasin L, Marczin N, Landoni G. Impact of low tidal volumes during one-lung ventilation. A meta-analysis of randomized controlled trials. J Cardiothorac Vasc Anesth. 2017;31:1767-73.

17. Hatipoglu Z, Turktan M, Avci A. The anesthesia of trachea and bronchus surgery. J Thorac Dis. 2016;8:3442-51.
18. Misiolek H, Knapik P, Swanevelder J, Wyatt R, Misiolek M. Comparison of double-lung jet ventilation and one-lung ventilation for thoracotomy. Eur J Anaesthesiol. 2008;25:15-21.

19. Ender J, Brodowsky M, Falk V, Baunsch J, Koncar-Zeh J, Kaisers UX, et al. High-frequency jet ventilation as an alternative method compared to conventional one-lung ventilation using double-lumen tubes during minimally invasive coronary artery bypass graft surgery. J Cardiothorac Vasc Anesth. 2010;24:602-7.

20. Pruszkowski O, Dalibon N, Moutafis M, Jugan E, Law-Koune JD, Laloë PA, et al. Effects of propofol vs sevoflurane on arterial oxygenation during onelung ventilation. Br J Anaesth. 2007.

21. Módolo NS, Módolo MP, Marton MA, Volpato E, Monteiro Arantes V, do Nascimento Junior $\mathrm{P}$, et al. Intravenous versus inhalation anaesthesia for one-lung ventilation. Cochrane Database Syst Rev. 2013;7:CD006313.

22. Lohser J, Slinger P. Lung injury after one-lung ventilation: a review of the pathophysiologic mechanisms affecting the ventilated and the collapsed lung. Anesth Analg. 2015;121:302-18.

23. Kim HJ, Kim E, Baek SH, Kim HY, Kim JY, Park J, et al. Sevoflurane did not show better protective effect on endothelial glycocalyx layer compared to propofol during lung resection surgery with one lung ventilation. J Thorac Dis. 2018;10:1468-75.

24. Haas S, Eichhorn V, Hasbach T, Trepte C, Kutup A, Goetz AE, et al. Goaldirected fluid therapy using stroke volume variation does not result in pulmonary fluid overload in thoracic surgery requiring one-lung ventilation. Crit Care Res Pract. 2012;2012:687018.

25. Cecconi M, De Backer D, Antonelli M, Beale R, Bakker J, Hofer C, et al. Consensus on circulatory shock and hemodynamic monitoring. Task force of the European Society of Intensive Care Medicine. Intensive Care Med. 2014:40:1795-815.

\section{Publisher's Note}

Springer Nature remains neutral with regard to jurisdictional claims in published maps and institutional affiliations.
Ready to submit your research? Choose BMC and benefit from:

- fast, convenient online submission

- thorough peer review by experienced researchers in your field

- rapid publication on acceptance

- support for research data, including large and complex data types

- gold Open Access which fosters wider collaboration and increased citations

- maximum visibility for your research: over $100 \mathrm{M}$ website views per year

At BMC, research is always in progress.

Learn more biomedcentral.com/submission 